\title{
A Straightforward Selective Acylation of Phenols over ZSM-5 towards Making Paracetamol Precursors
}

\author{
Robby Roswanda1, Alfhons D. Sirampun², Rino R. Mukti², Didin Mujahidin ${ }^{1, *}$ \\ ${ }^{1}$ Organic Chemistry Research Division, Faculty of Mathematics and Natural Sciences, Bandung \\ Institute of Technology, Jalan Ganesha 10, Bandung 40132, Indonesia \\ ${ }^{2}$ Inorganic and Physical Chemistry Research Division, Faculty of Mathematics and Natural Sciences, \\ Bandung Institute of Technology, Jalan Ganesha 10, Bandung 40132, Indonesia
}

Received: $29^{\text {th }}$ June 2018; Revised: $1^{\text {st }}$ August 2018; Accepted: $5^{\text {th }}$ August 2018;

Available online: $14^{\text {th }}$ November 2018; Published regularly: December 2018

\begin{abstract}
Commercially available ZSM-5 was minimally treated as the catalyst to selectively acylate phenols. The ZSM-5 was simply immersed in ammonium nitrate in order to fill the pores with Brönsted acid to concentrate the catalytic reactions inside the pores. The reactions were carried out in liquid phase at $383 \mathrm{~K}$. Acetic acid and propionic acid were chosen as the acyl substrate. Gas chromatography reveals two products which are phenyl acetate and almost exclusively para-hydroxyacetophenone meaning no ortho product observed. This para selectivity can be attributed to the pores of ZSM-5 where the reaction is assumed to be happening via intermolecular reaction. It is a relatively straightforward method in making para-hydroxyacetophenone which is known as paracetamol precursor. Copyright (C) 2018 BCREC Group. All rights reserved
\end{abstract}

Keywords: Acylation of Phenol; ZSM-5; Regioselectivity; Para-hydroxhyacetophenone

How to Cite: Roswanda, R., Sirampun, A.D., Mukti, R.R., Mujahidin, D. (2018). A Straightforward Selective Acylation of Phenols over ZSM-5 towards Making Paracetamol Precursors. Bulletin of Chemical Reaction Engineering \& Catalysis, 13 (3): 573-587 (doi:10.9767/bcrec.13.3.2856.573-587)

Permalink/DOI: https://doi.org/10.9767/bcrec.13.3.2856.573-587

\section{Introduction}

Acylation of phenol is an important step in organic synthesis since the products are key intermediates for a number of compounds. Both ortho-hydroxhyacetophenone (o-HAP) and parahydroxhyacetophenone ( $p$-HAP) are used in Hoechst-Celanese process to produce drug [1]. Separately, $p$-HAP is known to be used in making paracetamol $[2,3]$ meanwhile the $o$-HAP is an intermediate to make 4-hydroxycoumarin and warfarin, both known as anticoagulant drugs [4], and also to obtain flavanone via

\footnotetext{
* Corresponding Author.

E-mail: didin@chem.itb.ac.id (D. Mujahidin)

Telp: +62-22-2502103, Fax: +62-22-2504154
}

Claisen-Schmidt condensation [5,6]. In a similar reaction, acylation of resorcinol is also important as the product can be used for the production of valuable fine chemicals such as ipriflavone (antiosteopenic drug) and 4-O-octyl-2hydroxybenzophenone (UV-light absorbent for polymers) [7].

Hydroxhyacetophenone could be synthesized by Fries rearrangement of phenyl acetate or Friedel-Crafts direct acylation of phenol [8]. These reactions conventionally are catalyzed with homogeneous/heterogeneous Lewis Acid and Brönsted Acid catalysts [9]. The key challenge in this reaction is to tune the selectivity of the reaction whether to obtain the ortho, the pa$\mathrm{ra}$, or even to reduce the $\mathrm{O}$-acylation product 
which is usually phenyl acetate. Porous heterogeneous catalysts like zeolite have an advantage here since the pores can be engineered to selectively only allow one kind of products. Their homogeneous counterpart, usually metal halides, still have some inconvenience like the need to separate and some environmental issues because they are relatively toxic and corrosive [10].

The ratio of $o$-HAP dan $p$-HAP products depends on the reaction condition. Lower temperature usually favors the formation of $p$-HAP and higher temperature favors o-HAP [11]. The ratio of $p / o$ increases with lower amount of catalyst and reaches a constant at increased amount of catalyst and by using solvent with great polarity [7]. In previous study, HZSM-5 is utilized to catalyze Fries rearrangement of phenyl acetate at $170{ }^{\circ} \mathrm{C}$ to result a $p$-HAP selective reaction (p/o ratio: 6.0) [12]. When the similar reaction is carried over the same catalyst at $265{ }^{\circ} \mathrm{C}$, the selectivity changes to favor $o$ HAP (o/p ratio: 35.5) [13]. This shows the effect of temperature in tuning the selectivity of acylation. In the case of direct acylation, phenol is acylated with acetic anhydride over HZSM-5 that shows a very high ortho selectivity $(72.4 \%$ phenol conversion, $20.1 \%$ PA yield, $47.8 \% o$ HAP yield, $0.6 \% p$-HAP yield) [14]. Guisnet et al. carry out the acylation of phenol with activated acetic acid in gas phase that still results in higher ortho selectivity (o/p ratio: 16.0) [15]. One example that shows para selectivity is the acylation of phenol using benzoic anhydride over HBEA zeolites with p/o at 2.1 [16].

Here, we report acylation of phenols with acetic acid and propionic acid over protonated ZSM-5 with high para selectivity in liquid phase and relatively mild condition. We developed the method as straightforward as possible to reduce any complexity. Nevertheless, the selectivity of the acylation was surprisingly high towards the formation of $p$-HAP and little to none of $o$-HAP was observed. This simplistic method shows promise to generate total selectivity of phenol acylation.

\section{Materials and Methods}

\subsection{Materials and Equipments}

Propionic acid, acetic acid glacial, phenol and organic solvents were purchased from Merck. ZSM-5 ppore size $4.6 \AA$; $(0.9 \pm 0.2)$ $\left.\mathrm{H} \cdot \mathrm{Al}_{2} \mathrm{O}_{3} \cdot(25-50) \mathrm{SiO}_{2} \cdot 2 \mathrm{H}_{2} \mathrm{O}\right\}$ was purchased from Qingdao Wish Chemical. Electron Micrograph of ZSM-5 was recorded using JEOLJSM-6510LV Scanning Electron Microscope (SEM) under low vacuum, operated at 10-15
$\mathrm{kV}$. The XRD measurements of ZSM-5 were performed on Phillips Analytical X-ray PW1835 using $\mathrm{Cu}$ anode with wavelength of $1.5406 \AA$ A Quantification of products were carried out by gas chromatography (GC) using Techcomp GC-7900 with a flame ionization detector (FID) and a SGE ENX-5 capillary column (length $=15 \mathrm{~m}$, inner diameter $=0.25$ $\mathrm{mm}$, and film thickness $=0.25 \mu \mathrm{m}$ ). Temperature program for GC analyses was set at 100 $\circ \mathrm{C}$ for $1 \mathrm{~min}$ and raised to $190 \circ \mathrm{C}$ at rate of 30 $\circ \mathrm{C} / \mathrm{min}$ and from 190 to $210 \circ \mathrm{C}$ at rate of 10 $\circ \mathrm{C} / \mathrm{min}$. The temperature was finally kept for 5 $\min$ at $210 \circ \mathrm{C}$. The products were confirmed with ${ }^{1} \mathrm{H}$ - and ${ }^{13} \mathrm{C}-\mathrm{NMR}$ spectra recorded on an Agilent DD2 system operating at $500 \mathrm{MHz}\left({ }^{1} \mathrm{H}\right)$ and $125 \mathrm{MHz}\left({ }^{13} \mathrm{C}\right)$.

\subsection{Catalyst Preparation}

To a $250 \mathrm{~mL}$ solution of $1 \mathrm{M}$ ammonium nitrate was added $20 \mathrm{~g}$ of ZSM-5. The suspension was stirred at r.t. for $24 \mathrm{~h}$ followed by filtration. The white solid was dried in oven at $90{ }^{\circ} \mathrm{C}$ for $2 \mathrm{~h}$ and calcinated in the furnace at $550{ }^{\circ} \mathrm{C}$ for $6 \mathrm{~h}$. This process was repeated once more to ensure the protonation of the zeolite. The protonated zeolite was characterized before and after utilized as catalyst with XRD and SEM.

\subsection{Acylation of Phenol}

The $2.5 \mathrm{~g}$ protonated ZSM-5 in three neck round bottom flask was heated at $110{ }^{\circ} \mathrm{C}$ for 2 $\mathrm{h}$ under $\mathrm{N}_{2}$ atmosphere. The zeolite was cooled to r.t. before use. To the zeolite was added 21 mmol of phenol in $100 \mathrm{mmol}$ of acid. The mixture was heated at $110{ }^{\circ} \mathrm{C}$ and the reaction was monitored with thin layer chromatography. After $72 \mathrm{~h}$, the mixture was filtrated and purified with silica column chromatography (nhexane/EtOAc = 95:5). The products were characterized with NMR and GC-MS:

p-hydroxypropiophenone (p-HPP):

${ }^{1} \mathrm{H}$ NMR $\left(\mathrm{CD}_{3} \mathrm{OD}\right): \delta 7.87(2 \mathrm{H}, d, J=8.7 \mathrm{~Hz})$, $6.83(2 \mathrm{H}, d, J=8.7 \mathrm{~Hz}), 3.34(1 \mathrm{H}, s), 2.95(2 \mathrm{H}$, $q, J=7.3 \mathrm{~Hz}), 1.15(3 \mathrm{H}, t, J=7.3 \mathrm{~Hz}) .{ }^{13} \mathrm{C}$ NMR: $\delta$ 202.1, 163.7, 129.8, 131.6, 129.8, $116.2,32.1,8.9$.

Phenyl propionate $(P P)$ :

${ }^{1} \mathrm{H}$ NMR $\left(\mathrm{CDCl}_{3}\right): \delta 7.40(2 \mathrm{H}, t, J=7.8 \mathrm{~Hz})$, $7.23(1 \mathrm{H}, t, J=7.3 \mathrm{~Hz}), 7.11(2 \mathrm{H}, d, J=7.9$ $\mathrm{Hz}), 2.61(2 \mathrm{H}, q, J=7.5 \mathrm{~Hz}), 1.29(3 \mathrm{H}, t, J=$ $7.5 \mathrm{~Hz}) .{ }^{13} \mathrm{C}$ NMR: $\delta$ 172.9, $150.8,129.3,125.7$, $121.5,27.7,9.0$ 
p-hydroxyacetophenone (p-HAP):

${ }^{1} \mathrm{H} \mathrm{NMR}\left(\mathrm{CDCl}_{3}\right): \delta 7.92(2 \mathrm{H}, d, J=8.8 \mathrm{~Hz})$, $6.93(2 \mathrm{H}, d, J=8.6 \mathrm{~Hz}), 2.58(3 \mathrm{H}, s) .{ }^{13} \mathrm{C}$ NMR: $\delta 198.4,161.2,131.3,129.9,115.6,26.4$

\section{Phenyl acetate (PA):}

${ }^{1} \mathrm{H} \mathrm{NMR}\left(\mathrm{CDCl}_{3}\right): \delta 7.41(2 \mathrm{H}, t, J=8.0 \mathrm{~Hz})$, $7.23(1 \mathrm{H}, d, J=7.2 \mathrm{~Hz}), 7.12(2 \mathrm{H}, d, J=7.8$ $\mathrm{Hz}), 2.29(3 \mathrm{H}, \mathrm{s}) .{ }^{13} \mathrm{C}$ NMR: $\delta$ 169.4, 150.7, 129.3, 125.7, 121.5, 21.0.

Phenol conversion $\left(X_{p}\right)$ was calculated according to Equation (1), while product selectivity $\left(S_{i}\right)$ was calculated using Equation (2). In this equations, $\Sigma Y_{i}$ is total area of product, and $Y_{p}$ is area of phenol, and $X_{i}$ is area of product.

$$
\begin{aligned}
X_{p} & =\frac{\sum Y_{i}}{\left(\sum Y_{i}+Y_{p}\right)} x 100 \% \\
S_{i} & =\frac{X_{i}}{\sum Y_{i}} \times 100 \%
\end{aligned}
$$

\section{Results and Discussion}

The ZSM-5 was protonated before use to have a Brönsted acid property along with the Lewis acid property from the ZSM-5 which will be important in the catalytic process. The pro-

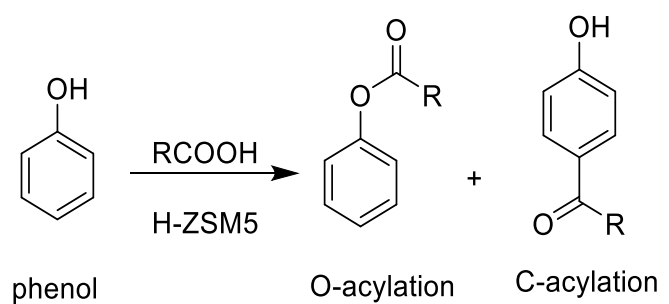

Scheme 1. Acylation of phenol; $\mathrm{R}=\mathrm{CH}_{3} ; \mathrm{C}_{2} \mathrm{H}_{5}$

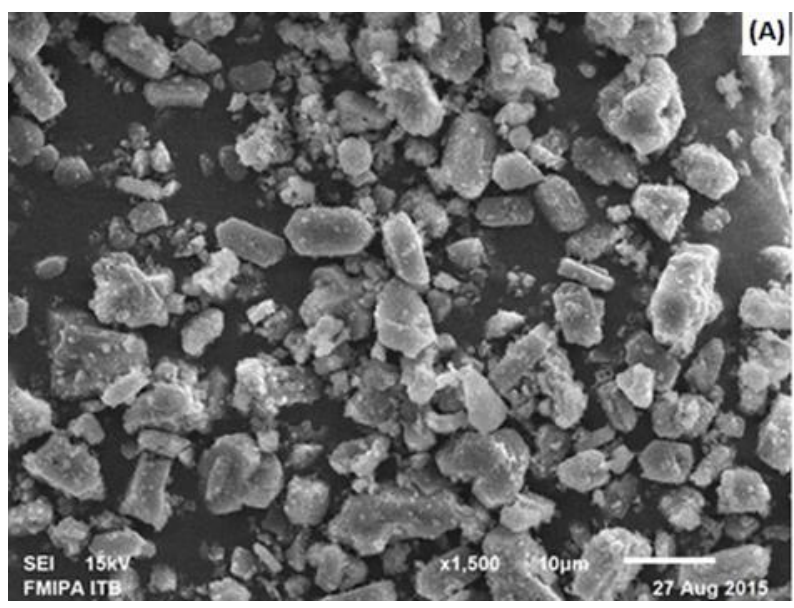

ton was designated only to be inside the pores of ZSM-5 by drying the zeolite after immersion in ammonium nitrate. This is to make sure that the Brönsted acids catalyze the reaction inside the pore, not outside, in order to increase selectivity. SEM images (Figure 1) show that the ZSM-5 has the shape like coffin and did not indicate any changes before and after protonation. XRD measurement also gave a similar diffractogram before and after protonation that suggests there is no significant change in morphology (Figure 2).

The acylation of phenol reactions were carried out for $72 \mathrm{~h}$ over ZSM-5 as the catalyst in a relatively mild condition $(383 \mathrm{~K})$ and liquid phase. There were two acyl substrates applied, acetic acid and propionic acid. After $24 \mathrm{~h}$ of reactions, the phenol was still observed and the reaction might have stopped at $24 \mathrm{~h}$ since no changes were observed after $24 \mathrm{~h}$. This might be the indication of deactivation of the catalyst has occurred after $24 \mathrm{~h}$.
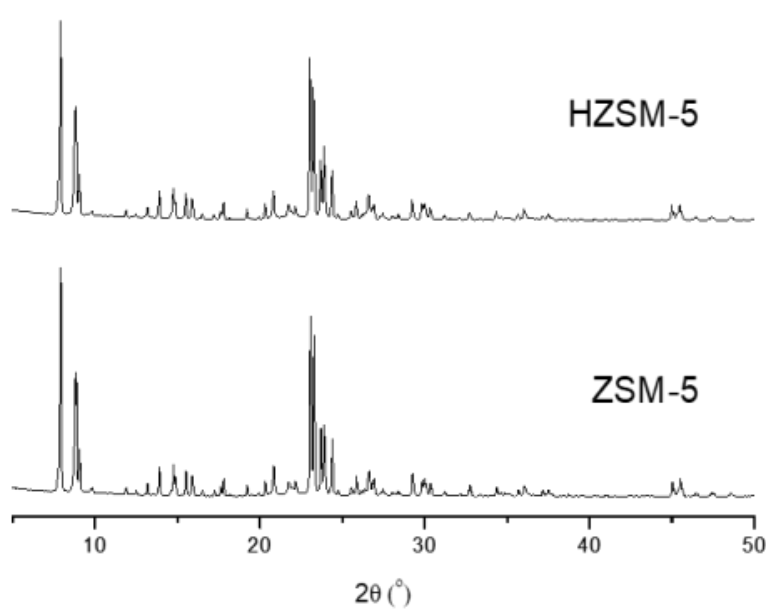

Figure 2. Difractogram of ZSM-5 before (bottom) and after (up) protonation

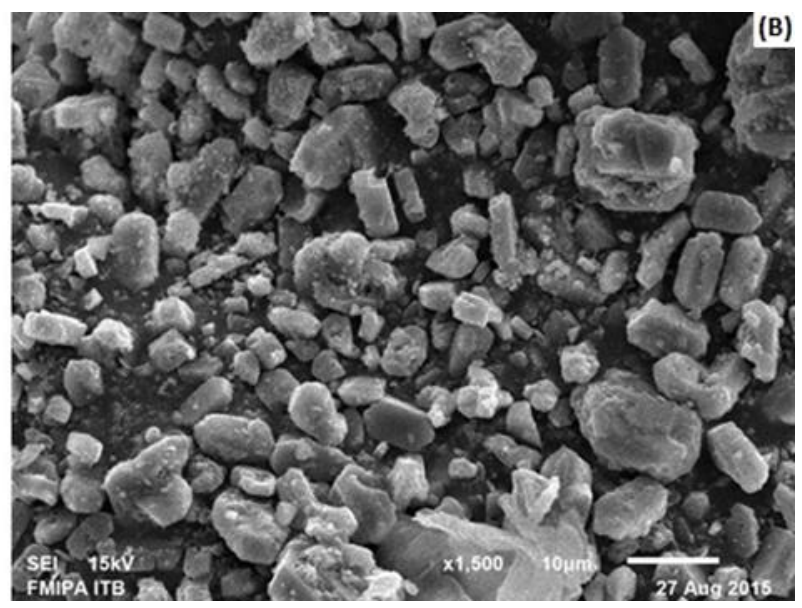

Figure 1. SEM micrographs of ZSM-5 (A) before and (B) after immersion with ammonium nitrate 
Gas Chromatography measurements of the crude show both substrates gave two products (see Electronic Supporting Information). After work up and purification, the products were checked in NMR. The NMR spectra confirmed that the two products obtained are $\mathrm{O}$-acylation as the major and the other is C-acylation. Oacylation products are phenylacetate (PA) and phenylpropionates (PP) meanwhile the Cacylation are $p$-hydroxyacetophenone (p-HAP) and $p$-hydroxypropiophenone ( $\mathrm{p}$-HPP). The reactions have moderate conversions at around $35 \%$. It is still a challenge to raise this conversion especially since phenyl acetate produced can also be reversed to produce phenol and ketene that reacts further with water to form acetic acid [8,17].

Table 1 shows the summary of acylation of phenol catalyzed by ZSM-5 on the two substrates. The remarkable part of the results was the selectivity of the $\mathrm{C}$-acylation that only produced para products for both of the substrates. No ortho products were observed that leads to the conclusion that the selectivity is almost 99 $\%$. The absence of ortho products gives a clue that the reaction might occurred inside the pore hence the exclusivity of the para products. The pores of ZSM-5 itself favor the insertions of para substituted benzenes than the ortho ones [18]. Inside the pores, the para products are formed via intermolecular reaction not intra molecular Fries rearrangement [19]. The reactions were indeed designed to occur inside the pores by removing the possible excess of Brosnted acid via drying the ZSM-5. It was also mentioned that lower temperature favor the formation para products [7]. Furthermore, $p$-hydroxyacetophenone can be formed through double acylation of the phenols followed by hydrolysis of the ester [15,20].

\section{Conclusions}

A very high selectivity towards para product of acylation of phenol with acetic acid and propionic acid over HZSM-5 was achieved. The method is relatively straightforward since it is carried out in liquid phase, mild condition, and minimum preparation of catalyst. The high selectivity can be achieved because of the use of protonated ZSM-5 which has a unique porous characteristic, as well as the Lewis acidity, that suits this selective reaction. This is really a remarkable lead to further investigate total selective acylation over HZSM-5. A high selectivity of acylation of phenol towards ortho products is really important in the making of paracetamol precursors.

\section{Acknowledgments}

We would like to thank Riset Peningkatan Kapasitas ITB program for funding this research.

\section{References}

[1] Guisnet, M., Guidotti, M. (2006). Aromatic Acetylation in Catalysts for Fine Chemical Synthesis, John Wiley \& Sons, Ltd. pp. 69-94.

[2] Fritch, J.R., Fruchey, S.O., Horlenko, T., Aguilar, D.A., Hilton, C.B., Snyder, P.S., Seeliger, W.J. (1992). Production of Acetaminophen. U.S. Patent 5,155,273.

[3] Commarieu, A., Hoelderich, W., Laffitte, J.A., Dupont, M.-P. (2002). Fries Rearrangement in Methane Sulfonic Acid, an Environmental Friendly Acid. Journal of Molecular Catalysis A: Chemical, 182-183: 137-141.

[4] Uwaydah, I.M., Aslam, M., Brown II, C.H., Fitzhenry, S.R., Mcdonough, J.A. (1997). Syntheses Based on 2-Hydroxyacetophenone. U.S. Patent 5,696,274.

Table 1. Conversion of acylation of phenol and the selectivity of the products

\begin{tabular}{|c|c|c|c|c|}
\hline \multirow{3}{*}{ Acid substrate } & \multirow{3}{*}{$\%$ phenol conversion ${ }^{\mathrm{a}}$} & \multicolumn{3}{|c|}{ Product Selectivity (\%) } \\
\hline & & \multirow{2}{*}{$\begin{array}{c}\text { O-acylation } \\
\text { (Ester) }\end{array}$} & \multicolumn{2}{|c|}{ C-acylation } \\
\hline & & & Para-product & Ortho-product \\
\hline Acetic acid & 32 & 74 & 26 & 0 \\
\hline Propionic acid & 40 & 62 & 38 & 0 \\
\hline
\end{tabular}


[5] Drexler, M.T., Amiridis, M.D. (2003). The Effect of Solvents on the Heterogeneous Synthesis of Flavanone over MgO. Journal of Catalysis, 214: 136-145.

[6] Climent, M.J., Corma, A., Iborra, S., Primo, J. (1995). Base Catalysis for Fine Chemicals Production: Claisen-Schmidt Condensation on Zeolites and Hydrotalcites for the Production of Chalcones and Flavanones of Pharmaceutical Interest. Journal of Catalysis, 151: 60-66.

[7] Sartori, G., Maggi, R. (2011). Update 1 of: Use of Solid Catalysts in Friedel-Crafts Acylation Reactions. Chemical Reviews, 111: PR181PR214.

[8] Padró, C.L., Apesteguía, C.R. (2005). Acylation of Phenol on Solid Acids: Study of the Deactivation Mechanism. Catalysis Today, 107108: $258-265$.

[9] Ashforth, R., Desmurs, J.-R., (1996). Friedelcrafts Acylation: Interactions Between Lewis Acids/Acyl Chlorides and Lewis Acids/Aryl Ketones. in Industrial Chemistry Library, Jean-Roger, D., Serge, R., Eds. Elsevier. 8: 314.

[10] Das, D., Cheng, S. (2000). Friedel-Crafts Acylation of 2-Methoxynaphthalene over Zeolite Catalysts. Applied Catalysis A: General, 201: 159-168.

[11] Arata, K. (1991). Synthesis of Solid Superacids by Metal Oxides and their Catalytic Action. Trends in Physical Chemistry, 2: 1-24.

[12] Cundy, C.S., Higgins, R., Kibby, S.A.M., Lowe, B.M., Michael Paton, R. (1989). Paraselective Fries Rearrangement of Phenyl Acetate in the Presence of Zeolite Molecular Sieves. Tetrahedron Letters, 30: 2281-2284.

[13] Borzatta, V., Poluzzi, E., Vaccari, A. (2002). In Science and Technology in Catalysis, Anpo, M.; Onaka, M., Yamashita, H., Eds. Elsevier: Amsterdam. p 439.
[14] Subba Rao, Y.V., Kulkarni, S.J., Subrahmanyam, M., Rama Rao, A.V. (1995). An Improved Acylation of Phenol over Modified ZSM-5 Catalysts. Applied Catalysis A: General, 133: L1-L6.

[15] Neves, I., Jayat, F., Magnoux, P., Pérot, G., Ribeiro, F.R., Gubelmann, M., Guisnet, M. (1994). Acylation of Phenol with Acetic Acid over a HZSM5 Zeolite, Reaction Scheme. Journal of Molecular Catalysis, 93: 169-179.

[16] Chaube, V.D., Moreau, P., Finiels, A., Ramaswamy, A.V., Singh, A.P. (2002). A Novel Single Step Selective Synthesis of 4Hydroxybenzophenone (4-HBP) Using Zeolite H-Beta. Catalysis Letters, 79: 89-94.

[17] Padró, C.L., Sad, M.E., Apesteguía, C.R. (2006). Acid Site Requirements for the Synthesis of o-Hydroxyacetophenone by Acylation of Phenol with Acetic Acid. Catalysis Today, 116: 184-190.

[18] Armaroli, T., Bevilacqua, M., Trombetta, M., Alejandre, A.d.G., Ramirez, J., Busca, G. (2001). An FT-IR Study of the Adsorption of Aromatic Hydrocarbons and of 2,6-Lutidine on H-FER and H-ZSM-5 Zeolites. Applied Catalysis A: General, 220: 181-190.

[19] Pouilloux, Y., Bodibo, J.P., Neves, I., Gubelmann, M., Perot, G., Guisnet, M. (1991). Mechanism of Phenylacetate Transformation on Zeolites. In Studies in Surface Science and Catalysis, M. Guisnet, J.B.C.B.D.D.G.P.R.M., Montassier, C., Eds. Elsevier. 59: 513-522.

[20] Chaube, V.D., Moreau, P., Finiels, A., Ramaswamy, A.V., Singh, A.P. (2001). Propionylation of Phenol to 4 Hydroxypropiophenone over Zeolite H-beta. Journal of Molecular Catalysis A: Chemical, 174: 255-264. 


\section{Appendix}
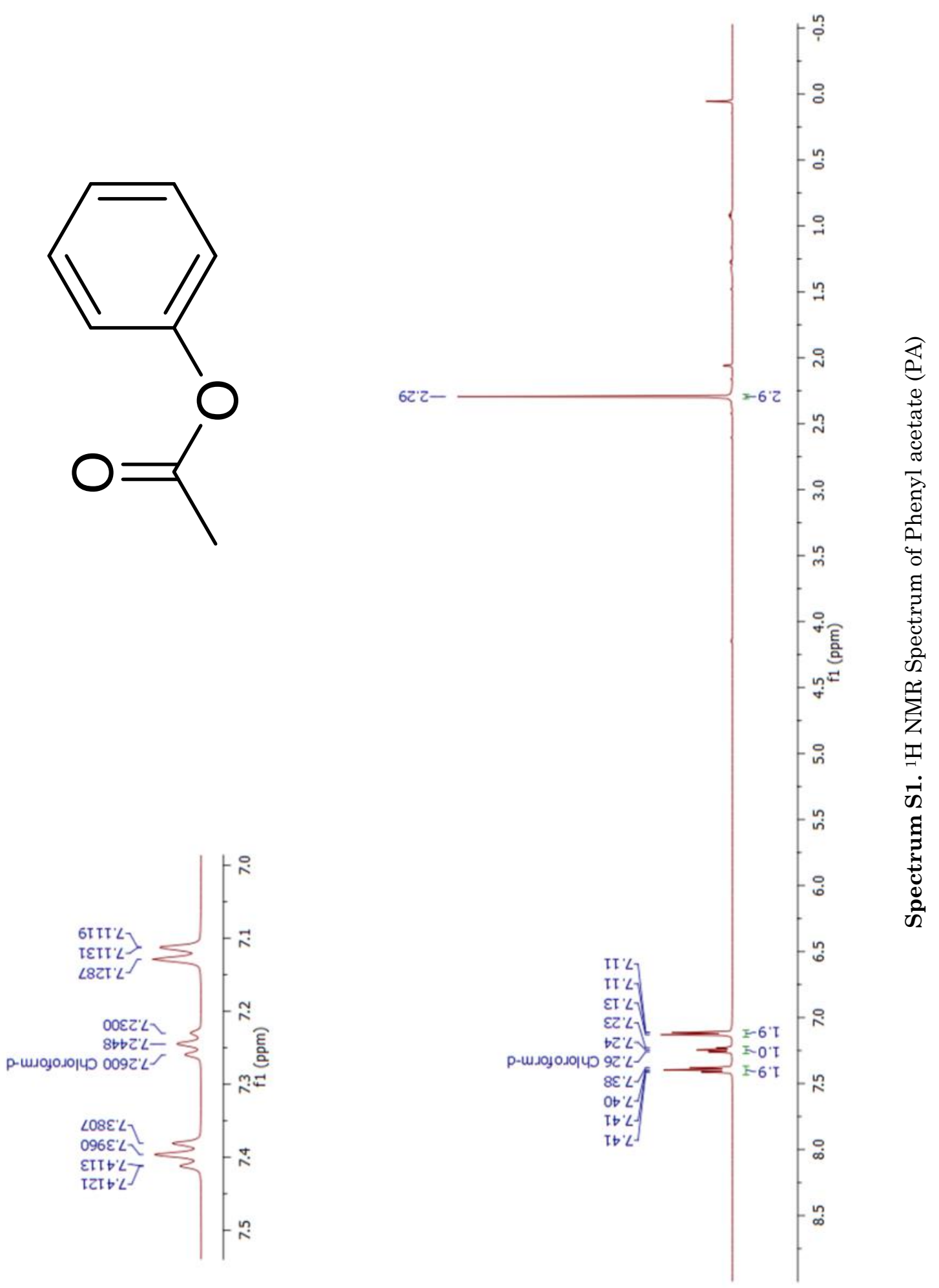


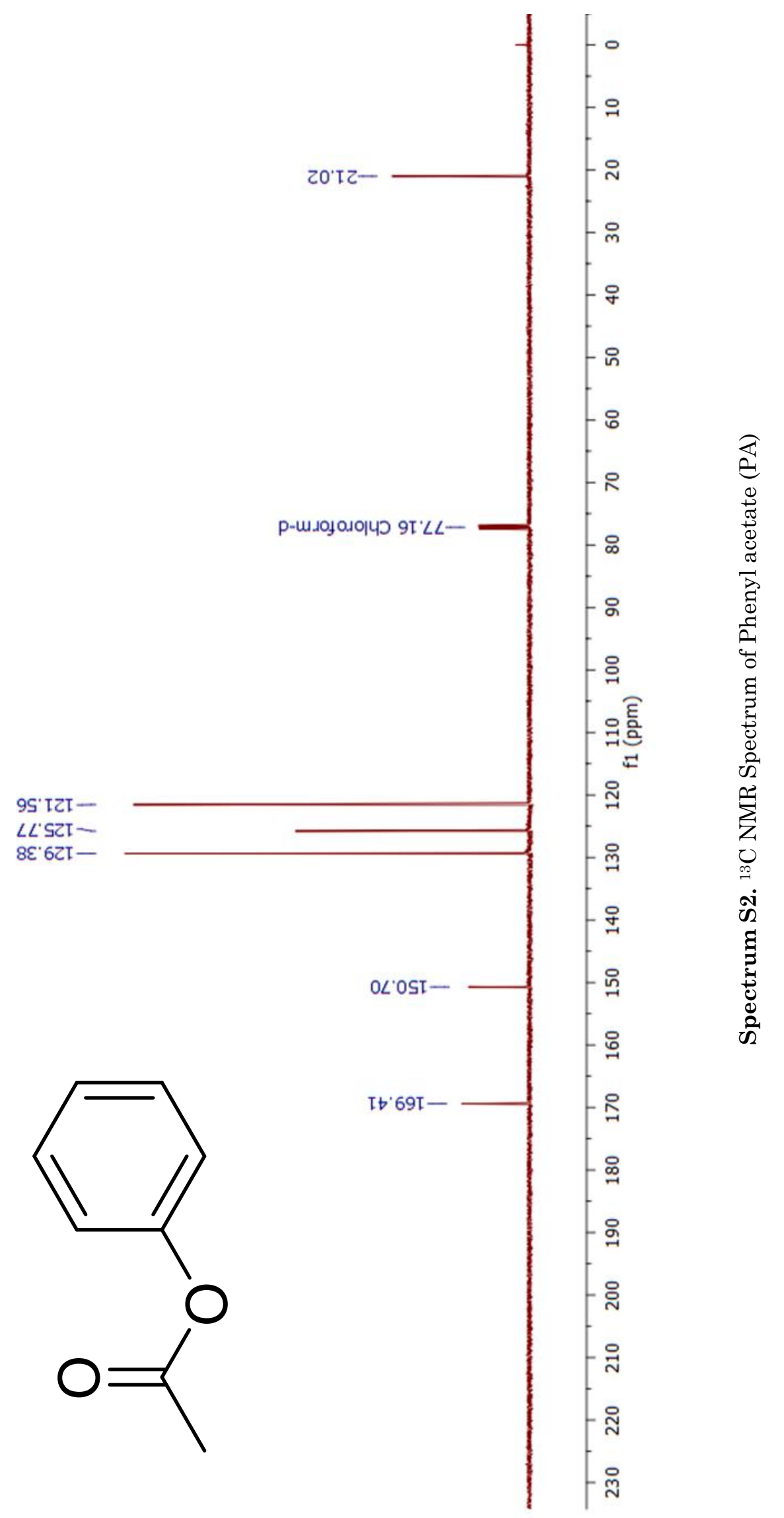




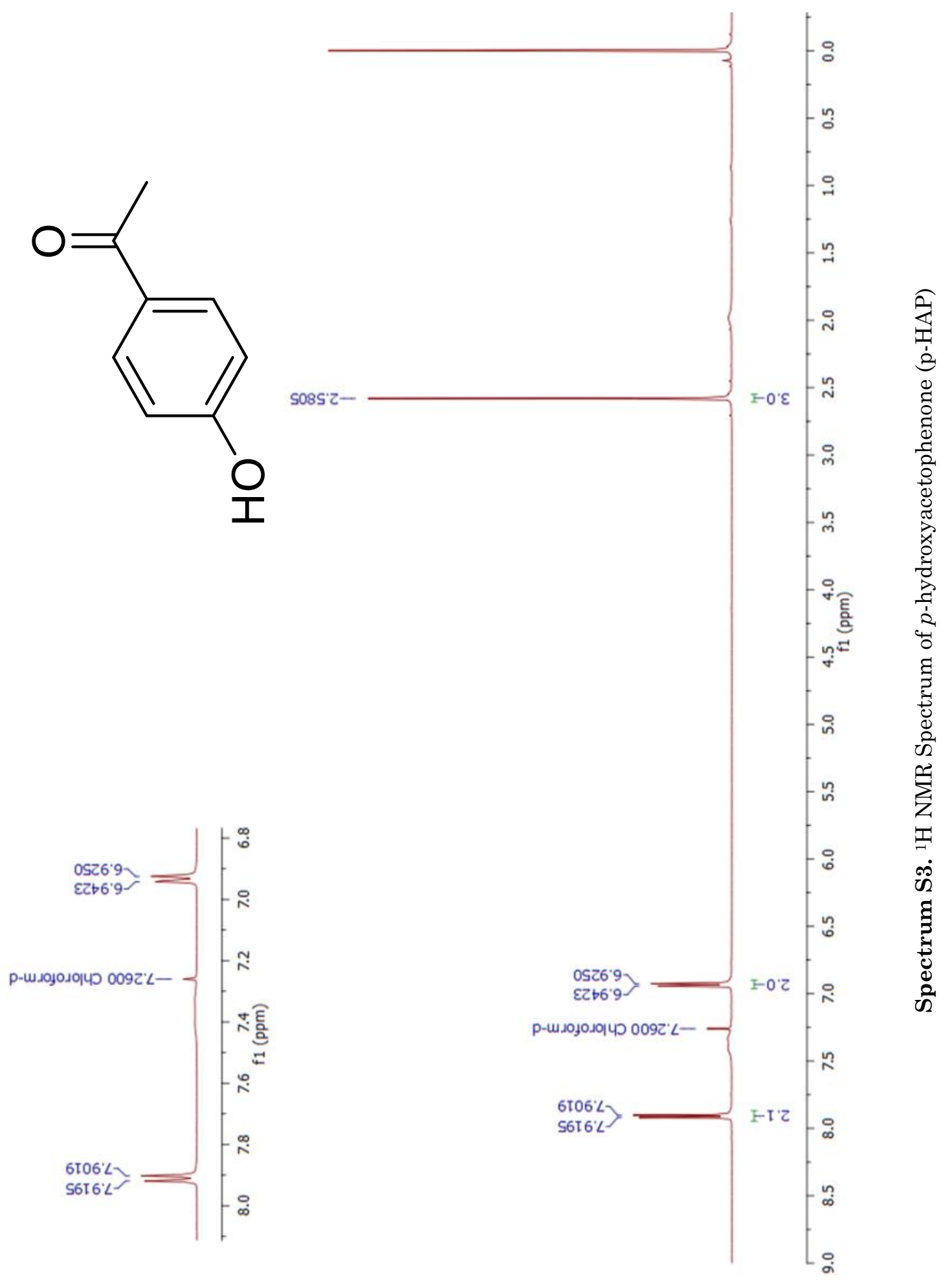




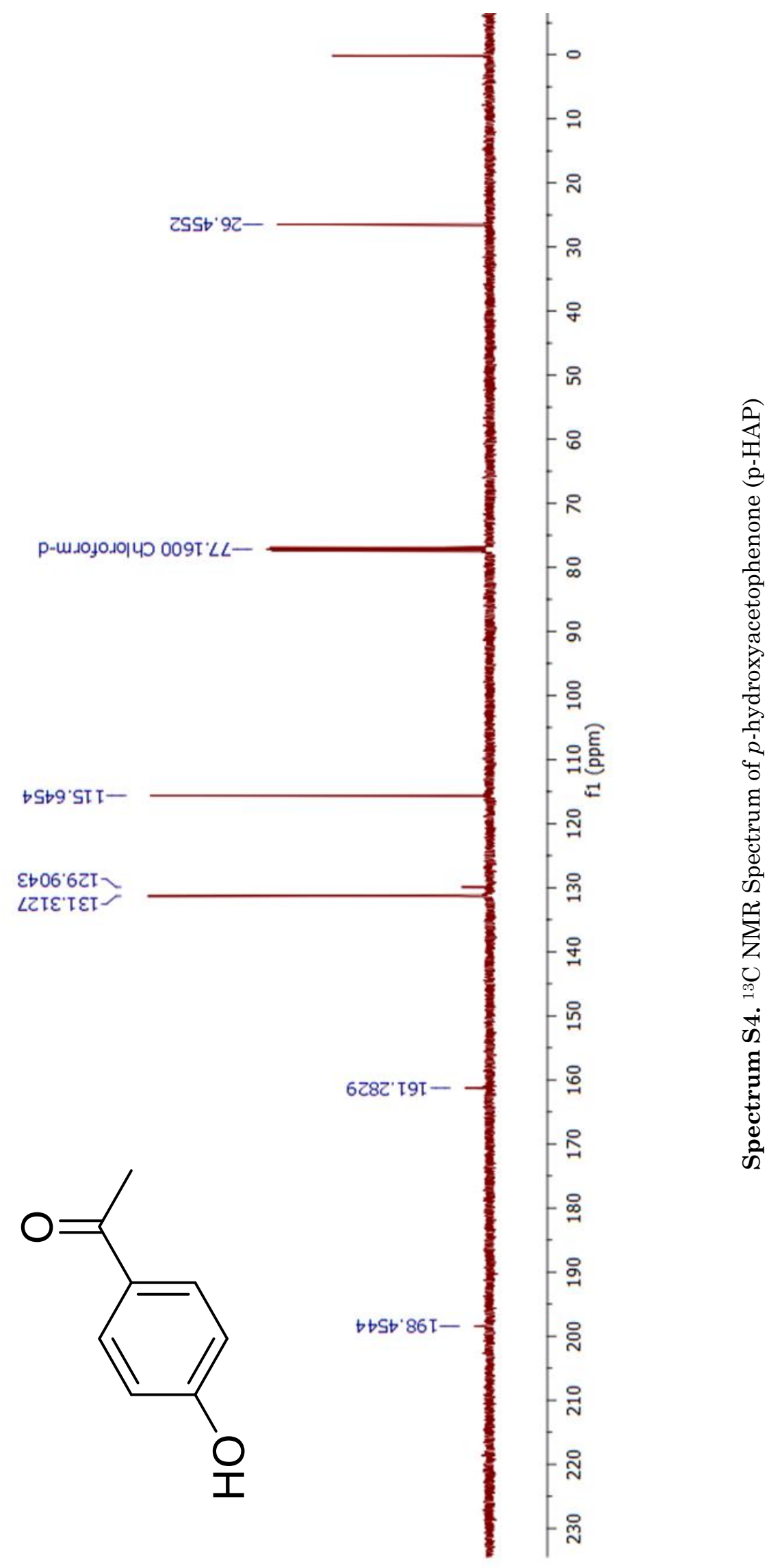




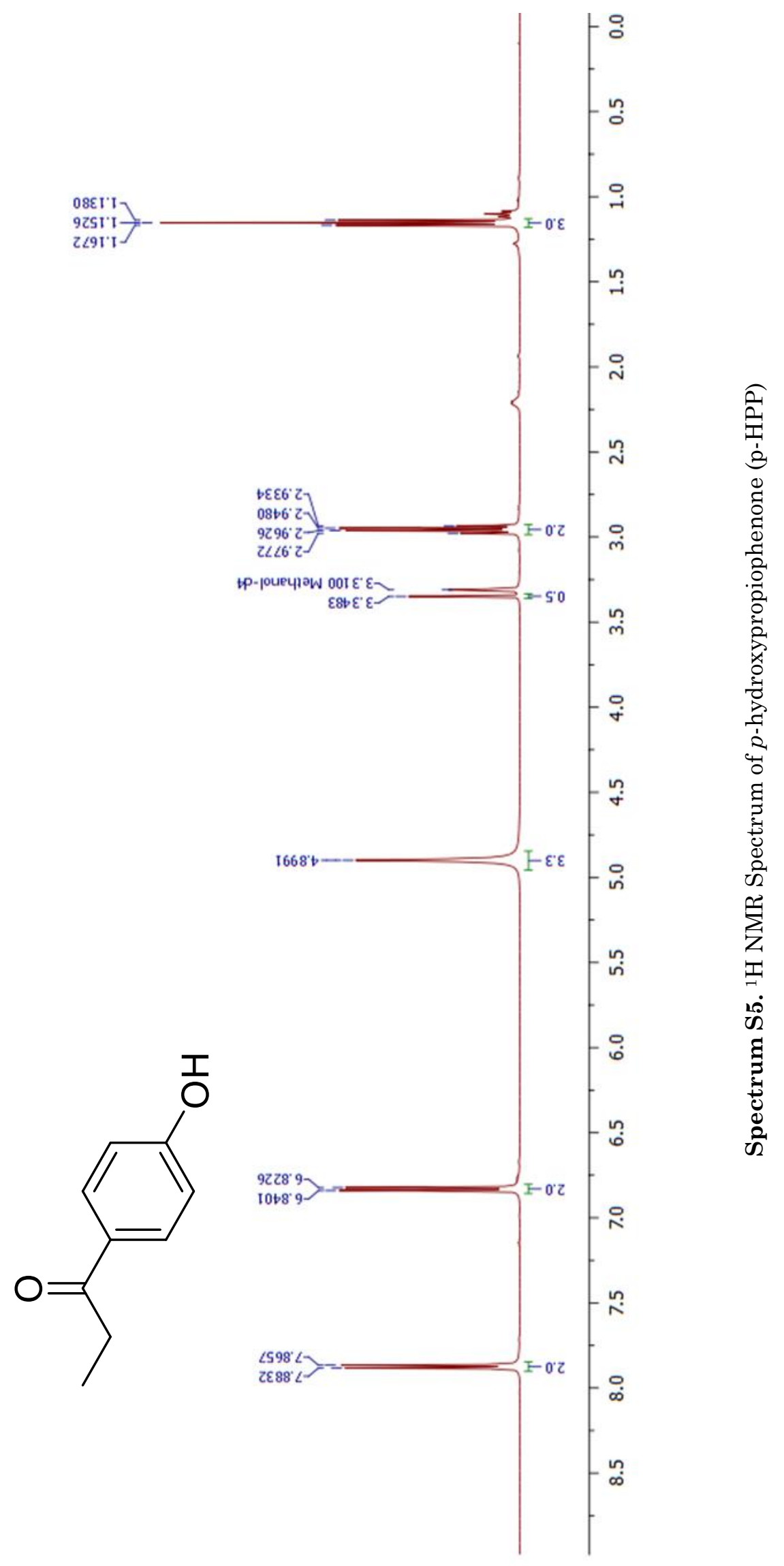




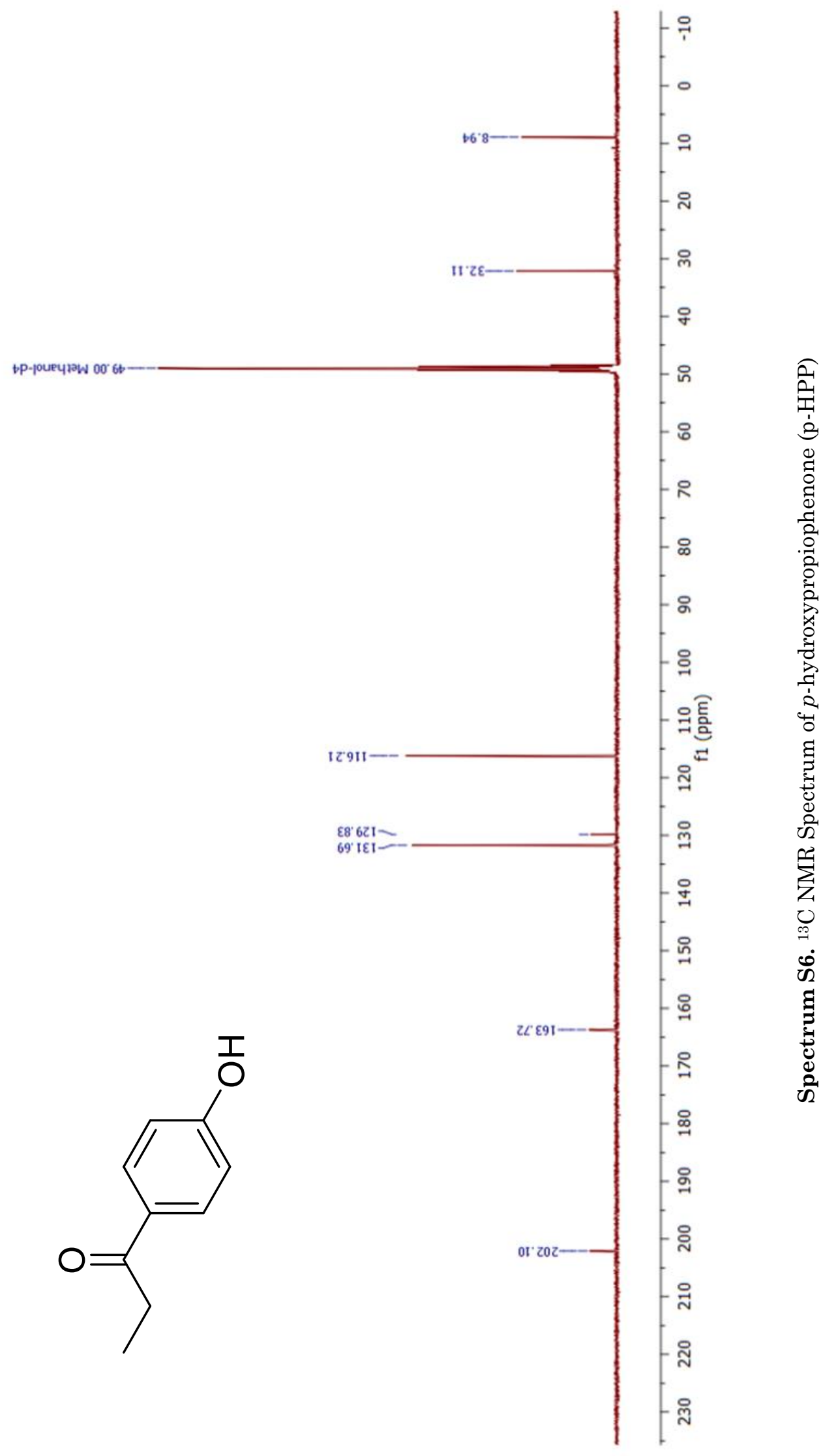




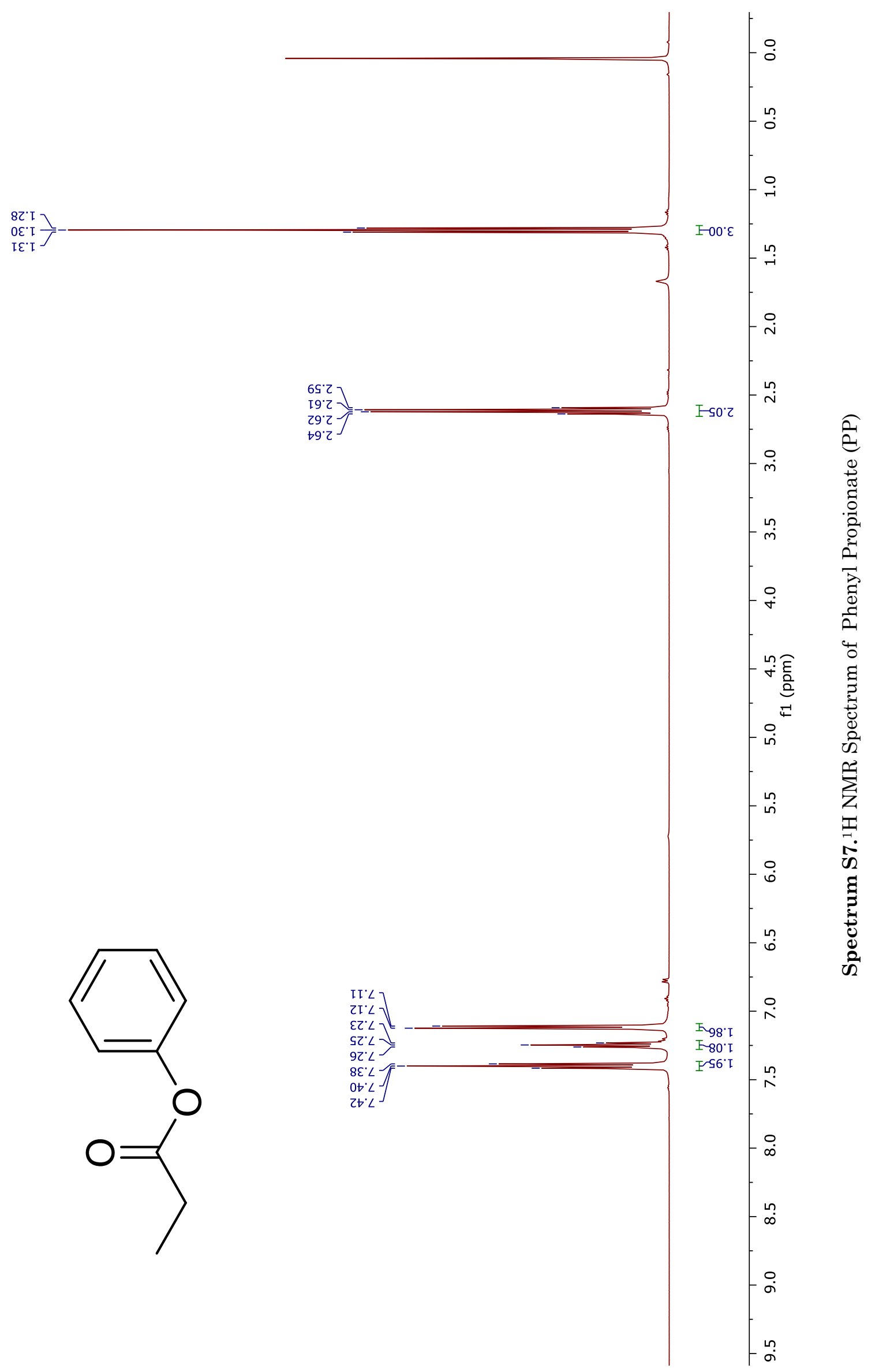




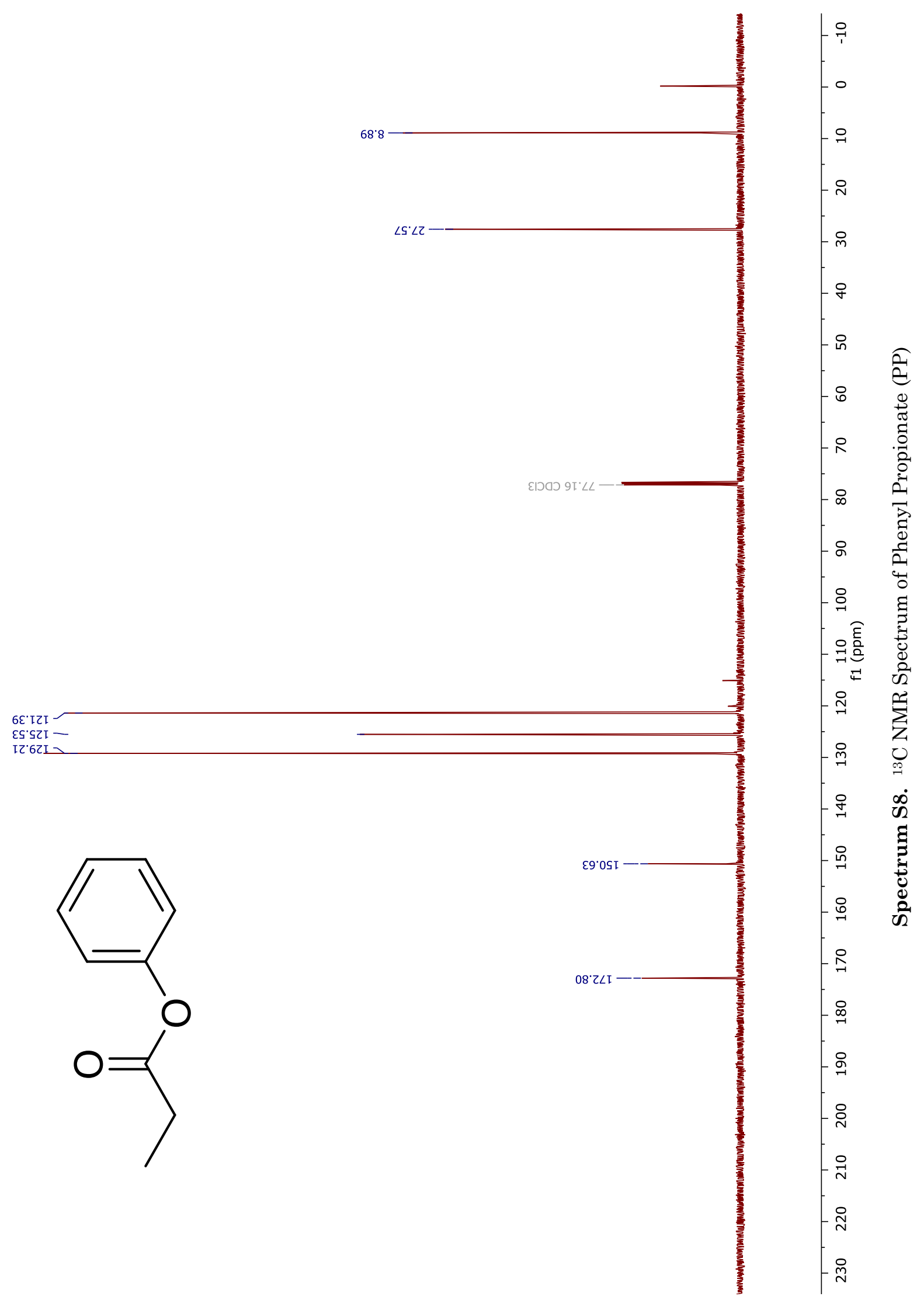


Chromatogram S9. Gas Chromatogram of Acetylation of Phenol

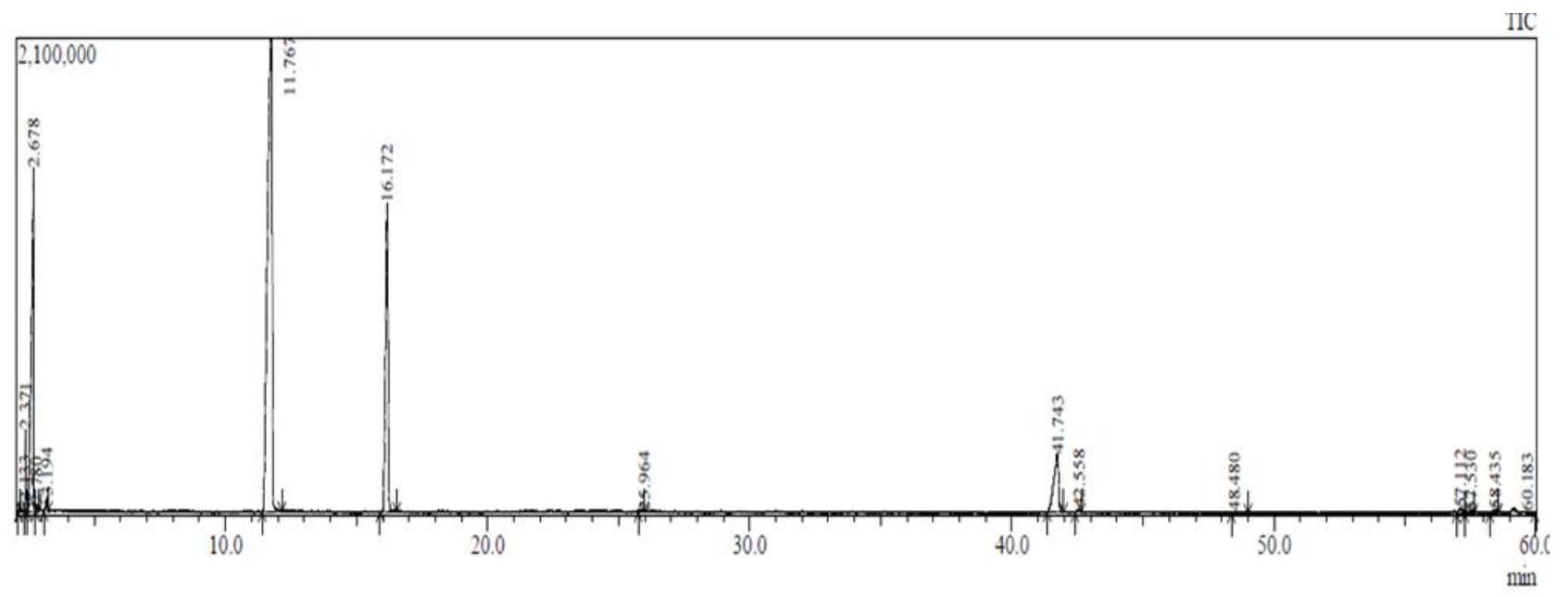

\begin{tabular}{|c|c|c|c|c|c|c|c|c|c|c|}
\hline \multirow[b]{2}{*}{ Peal= } & \multicolumn{10}{|c|}{ Peak Report ПC } \\
\hline & RTime & I.Time & F.Time & Area & Area $\%$ & Height & Height $\%$ & $\mathrm{AH}$ & Mark & Name \\
\hline 1 & 2.133 & 2.100 & 2.175 & 78606 & 0.15 & 39697 & 0.65 & 1.98 & & 1-Chloro-1-nitrosoethane \\
\hline 2 & 2.371 & 2.330 & 2.425 & 714738 & 1.38 & 360580 & 5.91 & 1.98 & $\mathrm{~V}$ & Acetic acid, methyl ester (CAS) Methyl acetate \\
\hline 3 & 2.678 & 2.450 & 2.745 & 9317168 & 18.03 & 1513039 & 24.80 & 6.16 & V & Acetic acid (CAS) Ethylic acid \\
\hline 4 & 2.780 & 2.745 & 2.855 & 110660 & 0.21 & 28767 & 0.47 & 3.85 & $\mathrm{~V}$ & Propanoic acid, methyl ester (CAS) Methyl pro \\
\hline 5 & 3.194 & 3.070 & 3.250 & 271071 & 0.52 & 66584 & 1.09 & 4.07 & $\mathrm{~V}$ & Propanoic acid (CAS) Propionic acid \\
\hline 6 & 11.767 & 11.400 & 12.155 & 27655484 & 53.52 & 2428028 & 39.80 & 11.39 & S & Phenol (CAS) Izal \\
\hline 7 & 16.172 & 15.895 & 16.535 & 9560309 & 18.50 & 1353156 & 22.18 & 7.07 & SV & Acetic acid, phenyl ester (CAS) Phenyl acetate \\
\hline 8 & 25.964 & 25.745 & 25.975 & 50131 & 0.10 & 5290 & 0.09 & 9.48 & $\mathrm{~V}$ & Hydrazine, [4-(trifluoromethoxy)phenyl]- \\
\hline 9 & 41.743 & 41.345 & 41.980 & 3300107 & 6.39 & 251916 & 4.13 & 13.10 & & Acetophenone, $4^{\prime}$-hydroxy. \\
\hline 10 & 42.558 & 42.405 & 42.655 & 93510 & 0.18 & 13483 & 0.22 & 6.94 & & 4-Acetoxyacetophenone \\
\hline 11 & 48.480 & 48.380 & 49.005 & 55257 & 0.11 & 2527 & 0.04 & 21.87 & & Acetic acid, 8-acetoxy-6-benzenesulfonyl-2-thy \\
\hline 12 & 57.112 & 56.955 & 57.280 & 162987 & 0.32 & 14681 & 0.24 & 11.10 & V & Benzenebutanal, gamma...gamma.4-trimethyl \\
\hline 13 & 57.530 & 57.280 & 57.630 & 123632 & 0.24 & 7477 & 0.12 & 16.53 & $\mathrm{~V}$ & \\
\hline 14 & 58.435 & 58.230 & 58.555 & 118795 & 0.23 & 9810 & 0.16 & 12.11 & V & Benzene, 1,1-(1,1,2,2-tetramethyl-1,2-ethaned \\
\hline 15 & 60.183 & 59.955 & 60.305 & 58284 & 0.11 & 6215 & 0.10 & 9.38 & & 1-Butanone, 1,4-bis(4-methylphenyl)- \\
\hline & & & & 51670739 & 100.00 & 6101250 & 100.00 & & & \\
\hline
\end{tabular}

Important Peaks

\begin{tabular}{clcc}
\hline Peak & R. Time & Compound & Area \\
\hline 6 & 11.767 & Phenol & 27655484 \\
7 & 16.172 & Phenyl Acetate (PA) & 9560309 \\
9 & 41.743 & $p$-hydroxyacetophenone (p-HAP) & 3300107 \\
\hline
\end{tabular}


Chromatogram S10. Gas Chromatogram of Propionalization of Phenol

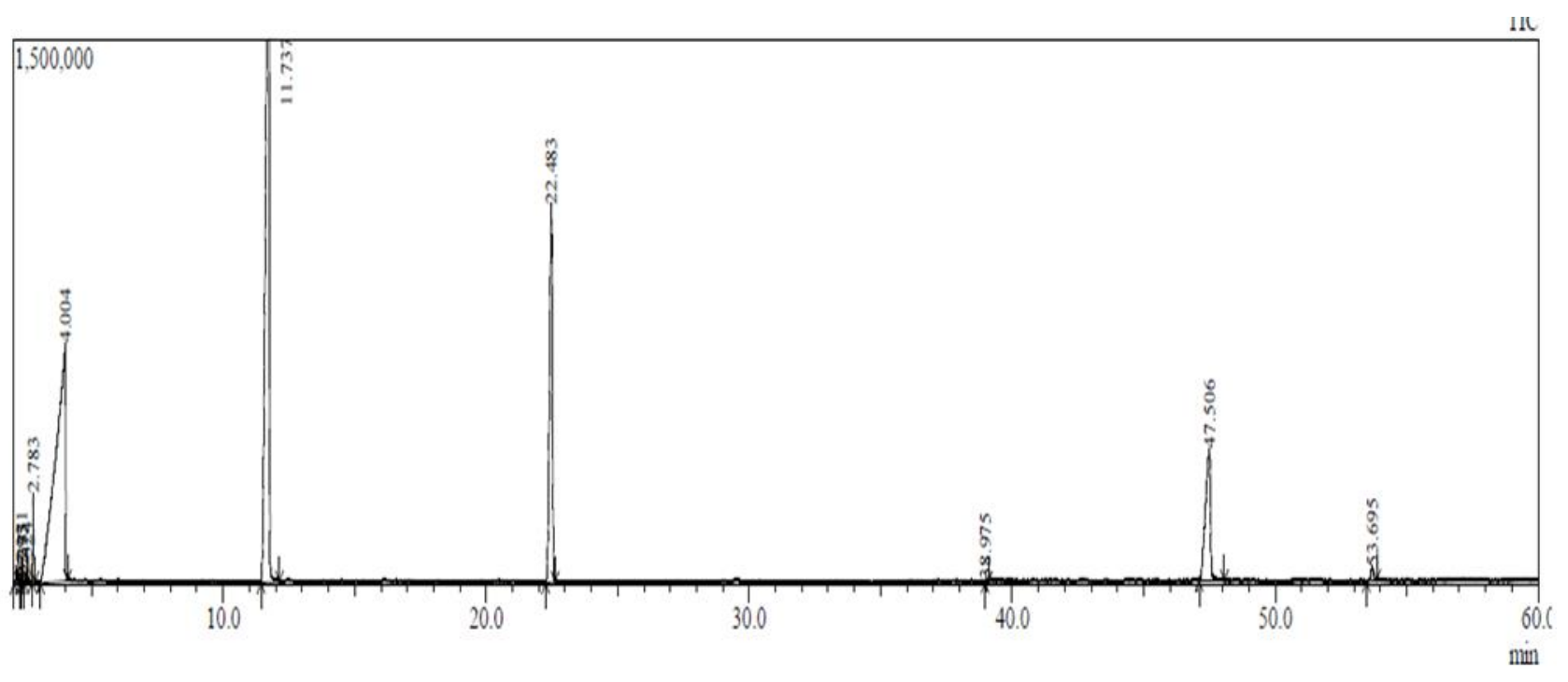

\begin{tabular}{|c|c|c|c|c|c|c|c|c|c|}
\hline \multirow[b]{2}{*}{ Peals $=$} & \\
\hline & RTime & ITime & FTime & Area & Area\% & Height & Heightr\% & AH Mark & Name \\
\hline 1 & 2.131 & 2.040 & 2.210 & 113156 & 0.23 & 46696 & 1.06 & $2.42 \mathrm{~V}$ & 1.Cliloro-1-nitrosoethane \\
\hline 2 & 22.297 & 2.250 & 2325 & 30333 & 0.06 & 11615 & 0.26 & $2.61 \mathrm{~V}$ & 2-Propanone (CAS) Acetone \\
\hline 3 & 2.375 & 2325 & 2.400 & 20051 & 0.05 & 12245 & 0.28 & $2.13 \mathrm{~V}$ & Acetic acid, methyl ester (CAS) Methy a cetate \\
\hline 4 & 2.524 & 2.40 & 2.575 & 73336 & 0.15 & 17435 & 0.40 & $4.21 \mathrm{~V}$ & Acetic acid (CAS) Ethylic acid \\
\hline 5 & 2.783 & 2.740 & 2.845 & 561354 & 1.12 & 244933 & 5.56 & 2.29 & Propanoic acid, methyl ester (CAS) Methyl pr \\
\hline 6 & 4.004 & 3.055 & 4.085 & 17005750 & 33.95 & 653354 & 14.83 & $26.03 \mathrm{~V}$ & Propanoic acid (C.AS) Propionic acid \\
\hline 7 & 11.737 & 11.440 & 12.135 & 19156998 & 38.25 & 1975776 & 44.85 & $9.70 \mathrm{SV}$ & Phenol (CAS) Izal \\
\hline 8 & 22.483 & 22.255 & 22.625 & 7963820 & 15.90 & 1041884 & 23.65 & $7.64 \mathrm{~V}$ & Propanoic acid, phenyl ester \\
\hline 9 & 38975 & 38.965 & 39.095 & 26413 & 0.05 & 5480 & 0.12 & $4.82 \mathrm{~V}$ & anti11,12 sym-12-4,4, 10exo-Tetrachloro-11 \\
\hline 10 & 47.506 & 47.115 & 48.065 & 4874840 & 9.73 & 360710 & 8.19 & 13.51 & Propanocic acid, phenyl ester (CAS) Phenyl pro \\
\hline 11 & 53.695 & 53.465 & 53.865 & 254515 & 0.51 & 35083 & 0.80 & 7.25 & Paroxypropione \\
\hline & & & & 50086566 & 100.00 & 405211 & 100.00 & & \\
\hline
\end{tabular}

Important Peaks

\begin{tabular}{clcc}
\hline Peak & R. Time & Compound & Area \\
\hline 7 & 11.737 & Phenol & 19156998 \\
8 & 22.483 & Phenyl Propionate (PP) & 7963820 \\
10 & 47.506 & $p$-hydroxypropiophenone $(p$-HPP) & 4874840 \\
\hline
\end{tabular}

